\title{
Correspondence
}

\section{Inconsistencies in risk assessment}

Sir: We were pleased to read the audit on risk assessment by Harwood \& Yeomans (Psychiatric Bulletin. July 1998, 22, 446-449) as it seems to be the first published audit on the topic in the country. However, as no audit standards were set, it would be more accurate to describe the article as a preliminary research survey. We wish to report the findings of an audit we recently carried out on the same topic.

For the purposes of the study we agreed on the following standards: every in-patient must have a risk assessment (either formal or informal); the management plan must reflect this assessment; a date of review should be set; and communication with other professionals should be adequate. The case notes of 22 consecutive inpatients to Bromsgrove and Redditch, in February 1998, were examined. Twenty-one patients had risk assessments, of which four were formal. The management plan and communications were adequate but assessments were not easily identifiable in the notes, and dates for review were not set.

As a result of the audit it was suggested that at the end of the clerking a clear statement is made of the level of risk as well as date of review set (e.g. ward round). The Trust is having discussions to agree uniform standards across hospitals and the audit will be repeated once the standards are agreed. Arguably the most significant finding was the degree of anxiety the topic caused to fellow clinicians. This raises the question which we believe has so far not been addressed (and probably explains the sparseness of publications on the topic): risk to whom are we really assessing? Is it the patient, the public, the trust or the professionals? The way the above question is answered could profoundly affect the doctor-patient relationship.

SARA SMITH, Registrar, D. SCHULTEWOLTER, Senior House Officer, F. SOUZA FARIA, Consultant Psychiatrist, Brook Haven. Princess of Wales Community Hospital, Stourbridge Road. Bromsgrove B61 OBB

Sir: Having completed an audit of risk assessment recording in medical case notes, it was interesting to read the paper by Harwood \& Yeomans (Psychiatric Bulletin, July 1998, 22, 446-449).
It was of no surprise that recording was found to be unsystematic and often unstructured. Although the Royal College of Psychiatrists (1996) have published guidelines for risk assessment and recommend it be completed for every patient, no national standard exists and local standards are few and far between.

Notably, Harwood \& Yeomans omitted to set an audit standard before proceeding with their work, to recommend standards after completion or to complete the audit cycle. The risk assessment tool was not standardised and had not been validated.

When designing our own audit, resistance from clinicians to formalising the risk assessment procedure was high. The implications, it was felt, of statements of risk was great, although accurate prediction is recognised as difficult (Ferris et al, 1997).

Assigning a level of risk, as Harwood \& Yeomans did, although convenient, is often misleading and meaningless. Risk is related to many factors (e.g. substance use, personal history, past behaviour and gender). These factors are not conveyed by a level or number. Routine weekly assignment of similar levels of risk in a regional secure unit was unhelpful and abandoned. Use of standardised tools has its own risk-a false sense that assessment is complete.

Although the requirement for more formal, structured risk assessment is increasing, perhaps emphasis should be on accessibility of clear, relevant information which is well communicated to the multi-disciplinary team, allowing each member to draw their own conclusion.

FERRIS, L. E., SANDERCOCK. J.. HOFFMAN, B., et al (1997) Risk assessments for acute violence to third parties: a review of the literature. Canadian Journal of Psychiatry. 42. 1051-1060.

ROYAL COLLEGE OF PSYCHIATRISTS (1996) Assessment and Clinical Management of Risk of Harm to Other People (Council Report CR53). London: Royal College of Psychiatrists.

S. SMITH, Senior House Officer in Learning Disabilities, Lea Castle Hospital, Lea Castle Drive, Wolverley, Near Kidderminster, West Midlands

\section{Maximum output of ECT machines}

Sir: Dykes \& Scott (Psychiatric Bulletin, May 1998, 22, 298-299) in their examination of 
seizure threshold in 100 people with depression. using an Ectron Series 5A, comment that this machine is not underpowered. Our experience contradicts this conclusion.

Recently, we used our Department's Ectron Series $5 \mathrm{~A}$ to treat an 87-year-old bald gentleman with a severe depressive illness characterised by agitation. minimal speech and poor food and fluid intake, who was resisting all interactions. He had a past history of two depressive episodes, the first 40 years ago was treated with electroconvulsive therapy (ECT) and the second in 1986 with dothiepin, which he had been maintained on since. Premorbidly he had been an anxious man with an active social life. There was no evidence of dementia. He had a history of ischaemic heart disease and ventricular tachycardia for which he took amiodarone $100 \mathrm{mg}$. He had an aortic aneurysm repair in 1986. He was prescribed aspirin for arteriosclerosis and thyroxine replacement therapy for hypothyroidism, diagnosed in 1986.

At commencement of ECT he was receiving clomipramine $10 \mathrm{mg}$ three times daily, $1 \mathrm{mg}$ trifluoperazine twice daily and zolpidem $10 \mathrm{mg}$ at night. Over the course of the ECT treatment the medication was altered to clomipramine $25 \mathrm{mg}$ three times daily and trifluoperazine $3 \mathrm{mg}$ twice daily. He also required intravenous fluids to maintain hydration.

ECT was given according to local protocol, using the stimulus dosing technique in line with College recommendations. The Ectron $5 \mathrm{~A}$ machine has a maximum output of 700 millicoulombs $(\mathrm{mC})$. The patient received a total of 21 electrode applications during 12 general anaesthetics. No satisfactory fit occurred until the maximum setting was used on the fourth and fifth general anaesthetics. No fit occurred on the sixth general anaesthetic, presumably due to increasing seizure threshold (Sackheim et al, 1987). Caffeine augmentation (250 $\mathrm{mg} \mathrm{iv}$ ) then produced satisfactory fits on the seventh and eighth general anaesthetics, but no further fits occurred.

Clinically this man remained severely depressed with low nutrient intake. In view of his condition he was transferred to the Manchester Royal Infirmary where a Thymatron DGX machine was available. Satisfactory fits occurred at $750 \mathrm{mC}$ and he is now making progress after seven general anaesthetics.

We therefore disagree with the conclusion that the Ectron Series 5A ECT machine is not significantly underpowered. For most patients it is adequate but for patients with a high seizure threshold, who are often elderly, it is underpowered and can result in crucial delays in the effective administration of this potentially lifesaving treatment.

SACKheim. H. A., Decina. P.. Prohovnik. I., et al (1987)

Seizure threshold in electroconvulsive therapy - effects of sex, age, electrode placement and number of treatments. Archives of General Psychiatry. 44, 355360.

Jean Galloway, Consultant Psychiatrist, ANDREW BLAKEY, Consultant Psychiatrist, East Cheshire NHS Trust, Macclesfield District General Hospital, Victoria Road. Macclesfield, Cheshire SK10 3BL; and SUSAN BENBOW, Consultant Psychiatrist, Carisbrooke Resource Centre, Wenlock Way, Gorton, Manchester M12 5LF

\section{Legal and contractual implications of the informal admission of psychiatric patients: a rejoinder}

Sir: Dr Azuonye (Psychiatric Bulletin. August $1998,22,501-505)$ states that "informal admission is the reception into hospital of a patient who either positively consents to admission or does not positively resist being taken into hospital". He is in fact describing two groups of patients, the former being voluntary patients, and the latter being informal patients. I would draw his attention to the comments of Lord Goff of Chieveley on 25 June 1998 in presenting the judgment of the House of Lords in the case of In Re: $L$ (by his next friend G.E.), who stated: "Both are admitted under section 131(1) without the formalities and procedures for admission necessary for detention under the Act. Strictly speaking, therefore, both groups could be described as informal patients but it is convenient to confine that description to those who are not voluntary patients".

Dr Azuonye points out that by virtue of accepting admission (presumably referring to voluntary patients) the patients agree to bide by the rules of the ward. He also implies that a voluntary admission places upon them an obligation of "refraining from unprovoked attacks on other patients and staff, not destroying hospital property". I would suggest that these are obligations that are incumbent upon all of us under common law, and not merely upon patients as a result of their voluntary admission to hospital.

Finally, Dr Azuonye states, again in accordance with good practice, "nursing and/or medical staff should be able to feel satisfied that any patient ... can safely go out of the hospital before allowing him or her to do so ..." and he goes on to quote the recent case of a young man who committed an armed robbery while out on a walk from his rehabilitation ward. I would suggest that the overriding issues that exercise the minds of health care professionals in making the sort of assessments that Dr Azuonye suggests are the risk of harm that the patient poses to himself and to others. Incidents such as the 